\title{
Development of a New Melon Cultivar 'Ibaraking' with High Fruit Growth Ability under Low Temperature Conditions, High Total Soluble Solid Content, and Resistance to Fusarium Wilt
}

\author{
Yuichi MATSUMOTO ${ }^{1 *}$, Tomoko ISHIKAWA and Makoto MIYAGI ${ }^{2}$ \\ Plant Biotechnology Institute, Ibaraki Agricultural Center (Kasama, Ibaraki 319-0292, Japan)
}

\begin{abstract}
'Ibaraking' is a new $\mathrm{F}_{1}$ melon (Cucumis melo L.) cultivar with green-fleshed fruit, high fruit growth ability under low-temperature conditions, high total soluble solid (TSS) content, and a long shelf life. It was developed from a cross between 2 parental lines P2 and P32 at the Plant Biotechnology Institute, Ibaraki Agricultural Center, Ibaraki, Japan. The parental line, P2, was fixed by self-pollination of a line selected from somaclonal variants of a cultivar 'Andes,' while another line, P32, was fixed by self-pollination of a cultivar 'Earl's Seine Natsu 2.' The fruit characteristics of 'Ibaraking' were compared with those of the common melon semi-forcing culture cultivars 'Andes-5' and 'Otome,' from 2005 to 2007, in semi-forcing culture by creeping cultivation. In 'Ibaraking,' low-temperature fruit growth ability and external appearance were equal to those of 'Otome' and exceeded those of 'Andes-5,' while the TSS content was similar to that of 'Andes-5' and exceeded that of 'Otome.' With regard to shelf life, 'Ibaraking' was superior to 'Otome' and equal to 'Andes-5.' In response to Fusarium wilt of melon, the most severe melon disease, 'Ibaraking' demonstrated resistance to races 0 and 2. These responses were identical to those of 'Andes-5' and 'Otome.' Therefore, we conclude that 'Ibaraking' appears a more suitable cultivar in semi-forcing culture by creeping cultivation in Ibaraki prefecture, Japan.
\end{abstract}

Discipline: Horticulture

Additional key words: Cucumis melo, Fruit firmness, Shelf life

\section{Introduction}

Melon (Cucumis melo L.) is one of the most important dessert cucurbits worldwide. In Japan, Ibaraki prefecture is the highest yielding production area, where 'Andes' (Sakata seed Corp., Japan) and 'Otome' (Takii seed Co. Ltd., Japan) cultivars are commonly grown. These cultivars have greenfleshed fruit and are cultivated in semi-forcing culture by creeping cultivation. However, they also often demonstrate inferior fruit growth or total soluble solid (TSS) content under low-temperature conditions in semi-forcing culture (Kaneko et al. 2005). Therefore, the popularity of these cultivars with farmers and consumers has declined, and development of a replacement is urgently required to maintain melon production in the area. In particular, fruit growth ability under low-temperature conditions is an important characteristic in the melon semi-forcing cultivar. In a previ- ous report, low-temperature germinability was reported as an indicator for selecting melon lines with fruit growth ability under low-temperature conditions, while lines with high fruit growth ability were developed from somaclonal variations (Ezura et al. 2005).

Fusarium wilt of melon caused by Fusarium oxysporum f. sp. melonis is considered the most severe melon disease. Once the disease colonizes a field, the pathogen survives in the soil because crop residues and roots of most crops, grown in rotation with melons, increase these persistent pathogenic populations. Fusarium strains are divided into 4 races $(0,1,2$, and 1,2$)$ based on their pathogenicity on a set of differential genotypes. Races 0 and 2 were generally observed in Japan, while resistant cultivars are effective for controlling such soilborne diseases in melons (Matsumoto et al. 2011, Namiki et al. 1998).

We developed a parental line from somaclonal variations in low-temperature germinability and Fusarium wilt

\footnotetext{
Present address:

${ }^{1}$ Faculty of Agriculture, Saga University (Saga, Saga 840-8502, Japan)

${ }^{2}$ Department of Agriculture, Forestry and Fisheries, Ibaraki Prefectural Government (Mito, Ibaraki 310-8555, Japan)

*Corresponding author: e-mail yumatsu@cc.saga-u.ac.jp

Received 17 July 2013; accepted 18 October 2013.
} 
resistance. The newly developed melon cultivar, 'Ibaraking', has high fruit growth ability under low-temperature conditions, high-quality green-fleshed fruit, including high TSS content, and resistance to the Fusarium wilt of melon races 0 and 2. Here we describe the breeding process and main fruit characteristics of the new melon cultivar 'Ibaraking.'

\section{Materials and Methods}

\section{Parental line and breeding process}

The parental line, P2, was fixed by self-pollination of a line selected from somaclonal variants of a cultivar 'Andes' with low-temperature germinability as an indicator of fruit growth ability under low-temperature conditions, according to the method of Ezura et al. (2005). It has high fruit growth ability under low-temperature conditions and resistance to Fusarium wilt races 0 and 2. Another parental line, P32, was fixed by self-pollination of a cultivar 'Earl's Seine Natsu 2' (Yae Nogei Co. Ltd., Japan) and is particularly palatable. These parental lines were used for the cross in 2003.

The $F_{1}$ cross combination was evaluated and selected in the experimental field and at farm sites from 2004 to 2007. Furthermore, 2 common semi-forcing cultivars in Ibaraki prefecture, 'Andes-5' and 'Otome,' were used for contrast with the $F_{1}$ cross combination.

\section{Evaluation of resistance to Fusarium wilt}

The response of 'Ibaraking' to Fusarium wilt races was compared with those of 'Andes-5' and 'Otome' and the parental lines P2 and P32. For the inoculation test, the fungal strains JCM 9889; Mel 02221; JCM 9288; and Fom 142-S1, which are classified as races $0 ; 1 ; 2$; and 1,2, respectively (Matsumoto et al. 2011, Namiki et al. 1998, 2000), were used. Inoculation was performed using a root dip method (Matsumoto et al. 2011). Each fungal strain was cultured in $100 \mathrm{~mL}$ of potato dextrose broth (PDB) in 300$\mathrm{mL}$ flasks on a rotary shaker (ca. $120 \mathrm{rpm}$ ) for 1 week at $25^{\circ} \mathrm{C}$, whereupon the culture was passed through a 2-ply gauze. The spore concentration, determined using a hemocytometer, was adjusted to the appropriate density $\left(10^{7}\right.$ spores $/ \mathrm{mL}$ ) by dilution with sterile distilled water. For artificial inoculation, seeds of the tested plants were sown into garden soil in plastic trays and grown in a growth chamber at $26-30^{\circ} \mathrm{C}$ and seedlings with a fully expanded first true leaf were removed from the soil. Their roots were washed using tap water and dipped in the conidial suspension for $15 \mathrm{~s}$. Inoculated seedlings were then transplanted to fresh garden soil in new plastic pots and cultivated in a growth chamber at $23^{\circ} \mathrm{C}$ ( $16 \mathrm{~h}$ photoperiod). The disease severity was evaluated 21 days after inoculation according to no symptoms or plant death. A total of 10 plants were evaluated for each cultivar.

\section{Evaluation of fruit characteristics}

The fruit characteristics of 'Ibaraking' were compared with those of 'Andes-5' and 'Otome' in semi-forcing culture by creeping cultivation in 2005-2007. Seedlings were planted in the greenhouse at $55-\mathrm{cm}$ intervals on February 7 and 10 and on January 18 in 2005, 2006, and 2007, respectively. Plants were topped at the $3^{\text {rd }}$ to $5^{\text {th }}$ node, 2 lateral shoots trained to creep were grown as the main stems, and 1 to 2 fruit per stem were set at the $11^{\text {th }}-15^{\text {th }}$ nodes. In total, 3 to 4 fruit were set per plant and mature fruit were harvested approximately 60 days after pollination. In all, 18-40 fruit per cultivar were evaluated each year. The means of weighing the fruit, TSS content, netting density, and netting thickness were determined using ripened melons, while TSS content was determined from the fruit juice extracted from sarcocarp of the equatorial region using a hand refractometer (ATC-1E, Atago Co. Ltd., Japan) and expressed as Brix. The netting density and netting thickness were scored on a 5-point scale and the results were as follows: density; $0=$ no netting, 3 = typical 'Andes' type (some of the epidermis was covered with netting), $4=$ most of the epidermis was covered with netting, and thickness; $0=$ no netting, $3=$ typical 'Andes' type (thick netting), 4 = typical Earl's type (very thick netting). Fruit firmness was measured to evaluate the shelf life of the melon according to the method of Johnstone et al. (2008). The harvested fruit were stored at $25^{\circ} \mathrm{C}$ for 1 and 7 days to allow the fruit to ripen. After storage, the fruit firmness was measured at 3 paired points along the equatorial region of the same fruit using a fruit hardness tester (KM-1, Fujiwara Factory, Japan) fitted with a 12-mm plunger and expressed as kilograms. In each cultivar, 8-20 fruit were evaluated for each period of stored days in 2007 and 2008. Analysis of variance (ANOVA) and tests of significance for all traits were performed, and a Tukey's honestly significant difference (HSD) post-hoc test was used for comparison. Analysis was performed using JMP statistical software (ver. 9.0.0; SAS Institute Inc., USA).

\section{Results and Discussion}

\section{Breeding and selection of 'Ibaraking'}

The parental lines P2 and P32 were fixed in 1999 and 2002 by self-pollination respectively and used for crossing in 2003 (Fig. 1). In 2004, $30 \mathrm{~F}_{1}$ hybrids from crosses between several parental lines, including P2 and P32, were grown in a greenhouse in semi-forcing culture, and line H421 was selected based on field performance and renamed Seiken-Ko-14. In 2005, 2006, and 2007, the line was evaluated in semi-forcing culture by creeping cultivation for agricultural characteristics, renamed Hitachi-Ko-3, and its local adaptability was evaluated at farm sites of Hokota city, Ibaraki prefecture, in semi-forcing culture by creeping cultivation in 2006 and 2007. Based on these data, we selected 
1991

\section{Andes}

1992

Plant regeneration from somatic embryogenesis
Regenerated line
1999

20032004

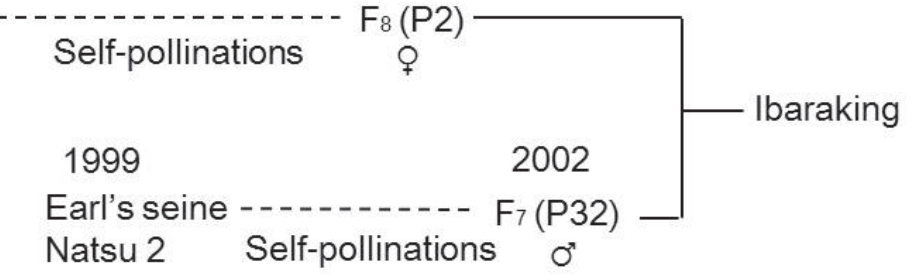

Fig. 1. The pedigree of 'Ibaraking' and parental lines
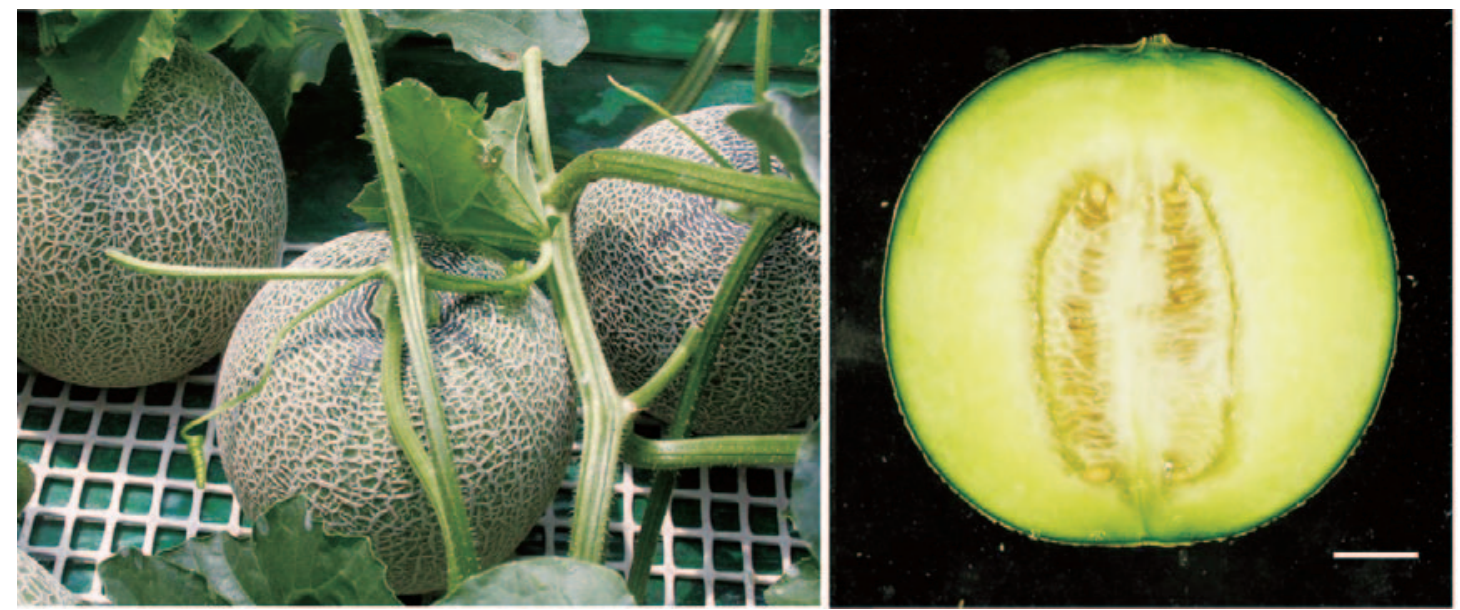

Fig. 2. Mature fruit of 'Ibaraking' $($ Bar $=2 \mathrm{~cm})$

the line and subsequently officially registered 'Ibaraking' with the Ministry of Agriculture, Forestry and Fisheries of Japan. In 2010, 'Ibaraking' was assigned the cultivar registration number 19804 (Fig. 2).

\section{Resistance to Fusarium wilt}

For races 0 and 2, none of the seedlings of 3 cultivars and parental line $\mathrm{P} 2$ presented any symptoms. In contrast, for races 1 and 1,2; all seedlings of the 3 cultivars and both parental lines died (Table 1). Thus, 'Ibaraking' was considered resistant to race 0 and 2 , and the resistance was provided by the parental line $\mathrm{P} 2$. The resistant reaction of 'Ibaraking' resembled that of 'Otome' and 'Andes-5.'

\section{Fruit characteristics}

Significant differences among the cultivars were also observed in fruit weight, TSS content, and netting density but not netting thickness. In addition to significant differences among cultivars and years, there were significant year by cultivar interactions for fruit weight, TSS content, and netting density (Table 2). In 'Ibaraking,' the fruit weight resembled that of 'Otome' and exceeded that of 'Andes-5.' TSS content resembled that of 'Andes-5' and exceeded that of 'Otome,', while the netting density was similar to that of 'Otome' and exceeded that of 'Andes-5' (Figs. 3, 4). From the fruit weight and netting density results, the fruit growth ability under low-temperature conditions and the external
Table 1. Pathogenicity of Fusarium oxysporum f. sp. melonis races to three melon cultivars and parental lines

\begin{tabular}{lcccc}
\hline \hline \multirow{2}{*}{ Cultivar or line name } & \multicolumn{4}{c}{ Mean disease symptoms ${ }^{\mathrm{a}}$} \\
\cline { 2 - 5 } & \multicolumn{4}{c}{ Race } \\
\cline { 2 - 5 } & 0 & 1 & 2 & 1,2 \\
\hline Ibaraking & NS & PD & NS & PD \\
Otome & NS & PD & NS & PD \\
Andes-5 & NS & PD & NS & PD \\
P2 & NS & PD & NS & PD \\
P32 & PD & PD & PD & PD \\
\hline
\end{tabular}

${ }^{a} \mathrm{NS}=$ no symptoms and $\mathrm{PD}=$ plant death. $\mathrm{n}=10$.

appearance of 'Ibaraking' appeared similar to that of 'Otome' and superior than that of 'Andes-5.'

For fruit firmness, although no significant differences among cultivars were observed 1 day after harvest (DAH), significant differences were observed at 7 DAH (Table 3). The fruit firmness of 'Ibaraking' exceeded that of 'Otome' at $7 \mathrm{DAH}$. The firmness was $1.19,1.15$, and $1.12 \mathrm{~kg}$ at 1 $\mathrm{DAH}$, and $0.67,0.89$, and $0.83 \mathrm{~kg}$ at $7 \mathrm{DAH}$ in 'Otome,' 'Andes-5,' and 'Ibaraking,' respectively (Fig. 5). The shelf life of 'Ibaraking' was accordingly concluded to be equivalent to that of 'Andes-5' and superior to that of 'Otome.' For fruit distribution, the shelf life of the ripened fruit is 
Table 2. Result of two-factor analysis of variance (ANOVA) for several parameters among the three melon cultivars from 2005 to 2007

\begin{tabular}{llrrrr}
\hline \hline Parameter & & d.f. & Mean square & \multicolumn{1}{c}{$F$} & $P$ \\
\hline Fruit weight $(\mathrm{g})$ & Cultivar & 2 & 1835266 & 34.14 & $<0.001$ \\
& Year & 2 & 6350689 & 118.13 & $<0.001$ \\
& Year $\times$ cultivar & 4 & 838869 & 7.80 & $<0.001$ \\
& Error & 311 & 26881 & & \\
Total soluble solids content $\left({ }^{\circ}\right.$ Brix) & Cultivar & 2 & 70.33 & 15.44 & $<0.001$ \\
& Year & 2 & 439.45 & 96.45 & $<0.001$ \\
& Year $\times$ cultivar & 4 & 68.04 & 7.47 & $<0.001$ \\
Netting density scale & Error & 309 & 2.28 & & \\
& Cultivar & 2 & 13.34 & 72.21 & $<0.001$ \\
& Year & 2 & 18.46 & 99.88 & $<0.001$ \\
& Year $\times$ cultivar & 4 & 2.54 & 6.88 & $<0.001$ \\
Netting thickness scale & Error & 302 & 0.09 & & \\
& Cultivar & 2 & 11.60 & 1.96 & 0.14 \\
& Year & 2 & 14.79 & 2.49 & 0.08 \\
& Year $\times$ cultivar & 4 & 10.47 & 0.88 & 0.47 \\
\hline
\end{tabular}
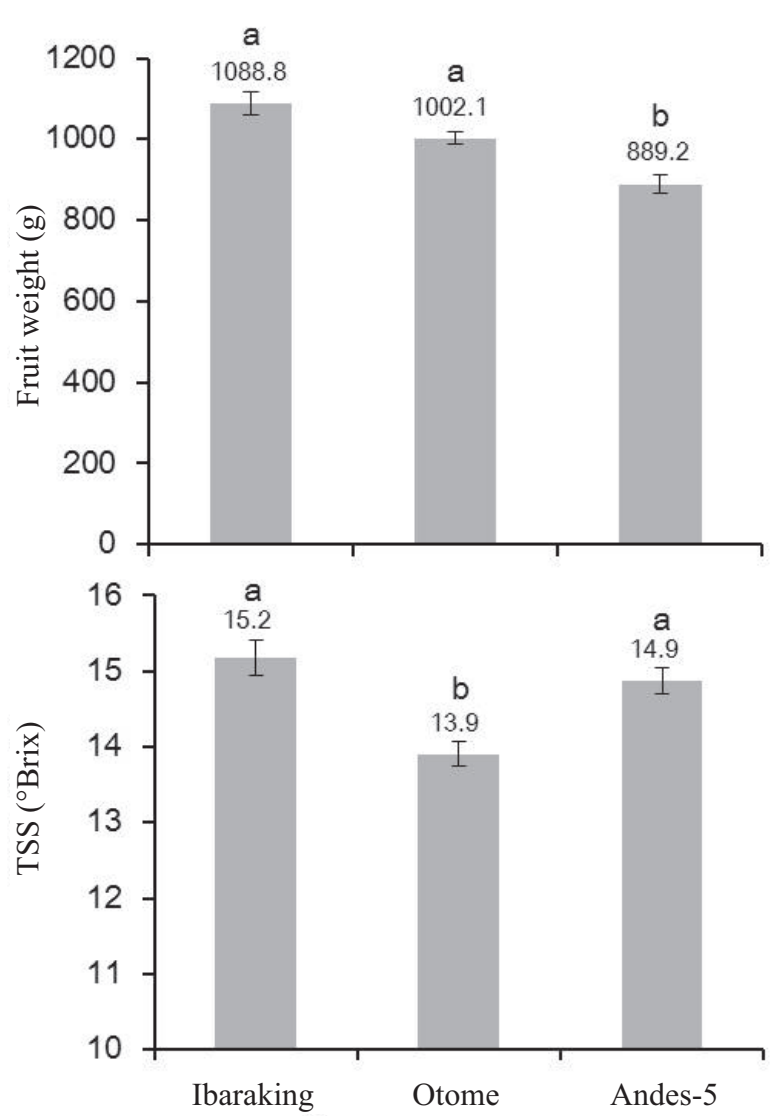

Fig. 3. Fruit weight and total soluble solid content of the 3 melon cultivars

The data shown are the means for 3 years (20052007) $(n=3)$. Identical superscript letters denote no significant differences between cultivars after Tukey's honestly significant difference (HSD) posthoc paired comparisons for pooled data for each cultivar. Error bar $=$ S.E.
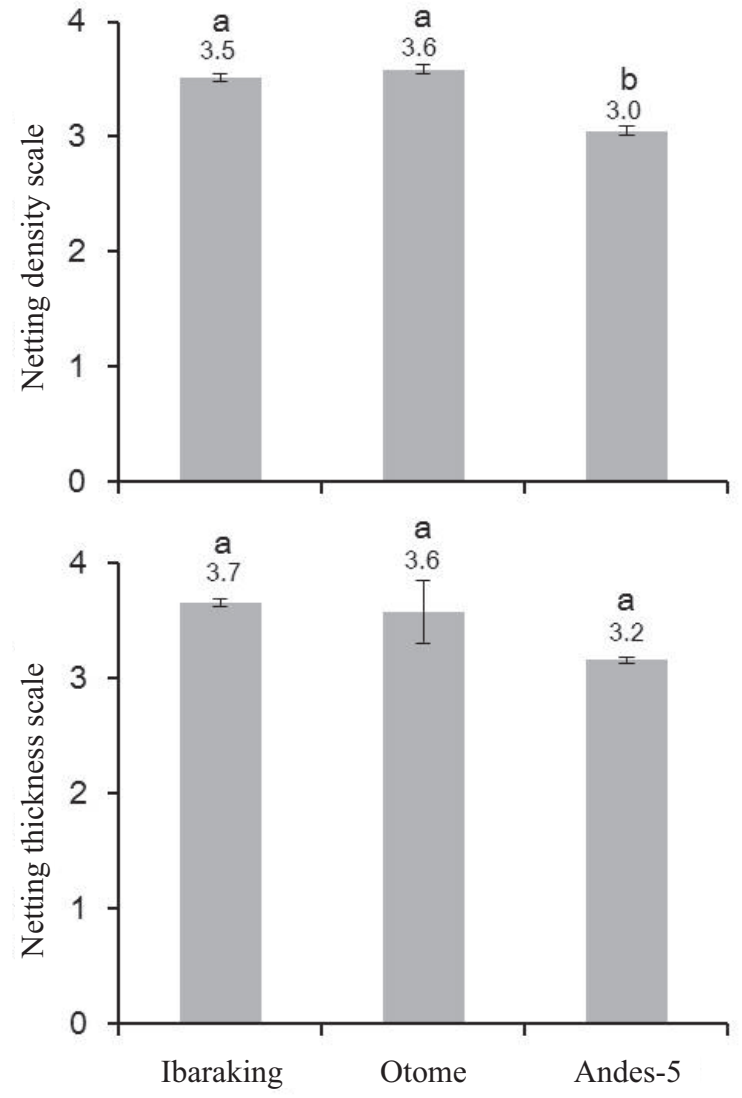

Fig. 4. Netting density and thickness scale of 3 melon cultivars

The data are the means for 3 years $(2005-2007)(n=$ $3)$. Identical superscript letters denote no significant differences between cultivars after Tukey's HSD post-hoc paired comparisons for pooled data for each cultivar. Error bar $=$ S.E. 
Table 3. Result of two-factor ANOVA for fruit firmness several days after harvest (DAH) in three melon cultivars from 2005 to 2007

\begin{tabular}{clrrrc}
\hline \hline DAH & & d.f. & $\begin{array}{r}\text { Mean } \\
\text { square }\end{array}$ & $F$ & $P$ \\
\hline \multirow{2}{*}{1} & Cultivar & 2 & 0.18 & 1.72 & 0.18 \\
& Year & 1 & 22.56 & 42.87 & $<0.001$ \\
& Year $\times$ cultivar & 2 & 0.10 & 0.97 & 0.38 \\
& Error & 76 & 0.05 & & \\
7 & Cultivar & 2 & 0.63 & 9.87 & $<0.001$ \\
& Year & 1 & 2.65 & 82.12 & $<0.001$ \\
& Year $\times$ cultivar & 2 & 0.24 & 3.82 & 0.02 \\
& Error & 81 & 0.03 & & \\
\hline
\end{tabular}

important and that of 'Andes-5' was relatively long for Japanese melons. We propose accordingly that it is as suitable for Japanese distribution as 'Andes-5.'

In the previous study, the adaptation of 4 melon cultivars in semi-forcing culture by creeping cultivation in Ibaraki prefecture was evaluated, and 2 cultivars, 'Otome' and 'Andes-5,' were suggested as suitable for semi-forcing culture (Kaneko et al. 2005). In this study, most fruit characteristics of 'Ibaraking' such as fruit growth ability under low-temperature conditions, TSS content, external appearance, and shelf life were similar to or superior to that of the other 2 cultivars. Therefore, 'Ibaraking' appeared a more suitable cultivar in semi-forcing culture by creeping cultivation in Ibaraki prefecture and would contribute to melon production.

\section{Seed availability}

Seeds of 'Ibaraking' are multiplying every year and available from the Plant Biotechnology Institute, Ibaraki Agricultural Center for scientists, and Horticultural Ibaraki Promotion Association (Mito, Ibaraki, Japan) for Ibaraki prefectural farmers.

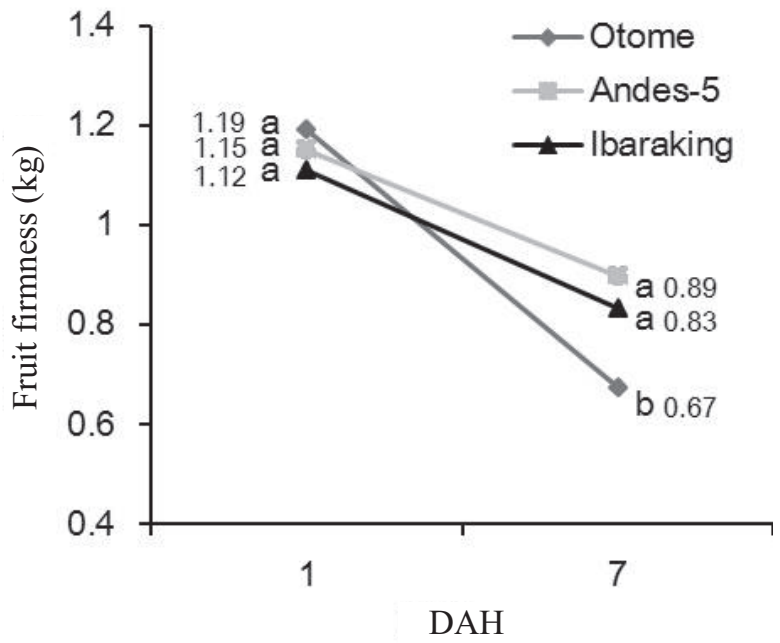

Fig. 5. Fruit firmness of the 3 melon cultivars at 1 and 7 days after harvest respectively

The data are the means for 3 years $(2005-2007)(n=$ 3). Identical superscript letters denote no significant differences between cultivars after Tukey's HSD post-hoc paired comparisons for pooled data for each cultivar.

\section{References}

Ezura, H. et al. (2005) Selection of somaclonal variants with low-temperature germinability in melon (Cucumis melo L.). Plant Cell Rep., 14, 684-688.

Johnstone, P. R. et al. (2008) Calcium fertigation ineffective at increasing fruit yield and quality of muskmelon and honeydew melons in California. HortTech., 18, 685-689.

Kaneko, K. et al. (2005) Selection of useful melon cultivars and a method of heat insulation in semi-forcing melon culture for harvesting in April. Bull. Hort. Inst., Ibaraki Agr. Cent., 13, 11-16 [In Japanese with English summary].

Matsumoto, Y. et al. (2011) Response of wild Cucumis species to inoculation with Fusarium oxysporum f. sp. melonis race 1,2y. J. Jpn. Soc. Hort. Sci., 80, 414-419.

Namiki, F. et al. (1998) Pathogenic and genetic variation in the Japanese strains of Fusarium oxysporum f. sp. melonis. Phytopathol., 88, 804-810.

Namiki, F. et al. (2000) Occurrence of Fusarium oxysporum $\mathrm{f}$. sp. melonis race 1 in Japan. J. Gen. Plant Pathol., 66, 12-17. 